AL IBTIDA: JURNAL PENDIDIKAN GURU MI (2017) VOL 4 (1): 97-108

DOI: http://dx.doi.org/10.24235/al.ibtida.snj.v4i1.1474

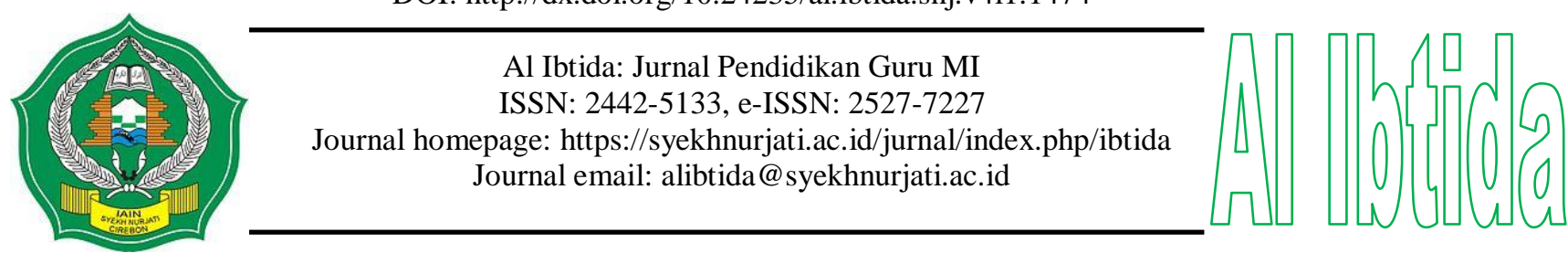

\title{
Pengaruh Penerapan Model Pembelajaran Auditory, Intellectually, Repetition (AIR) Terhadap Hasil Belajar Siswa Pada Mata Pelajaran Matematika Materi Pembagian Di Kelas IV MIN Gebang Udik Kecamatan Gebang Kabupaten Cirebon
}

\author{
Latifah* \\ *Jurusan Pendidikan Guru Madrasah Ibtidaiyah, Fakultas Ilmu Tarbiyah dan Keguruan, \\ IAIN Syekh Nurjati Cirebon \\ Email: latifah252@yahoo.co.id \\ Nurlaeli** \\ **Jurusan Pendidikan Guru Madrasah Ibtidaiyah, Fakultas Ilmu Tarbiyah dan Keguruan, \\ IAIN Syekh Nurjati Cirebon \\ Email: nurlaeli54@gmail.com
}

Received 12 April 2017; Received in revised form: 14 May 2017; Accepted 13 June 2017

Publish Online: 20 June 2017

\begin{abstract}
Abstrak
Penelitian ini dilatarbelakangi adanya kesulitan belajar yang dialami siswa dan kesulitan guru dalam mengajarkan matematika yang berdampak pada hasil belajar siswa yang masih sangat rendah. Rendahnya hasil belajar siswa tersebut, tentu saja banyak faktor yang menyebabkan, misalnya masalah klasik tentang penerapan metode pembelajaran matematika yang masih berpusat pada guru (teacher center), sehingga siswa cenderung pasif mendengarkan penjelasan guru. Penelitian ini bertujuan untuk mengetahui ada tidaknya pengaruh penerapan Model pembelajaran Auditory, Intellectually, Repetition (AIR) terhadap hasil belajar Matematika Materi Pembagian antara kelompok eksperimen yang menggunakan Model pembelajaran Auditory, Intellectually, Repetition (AIR) dengan kelompok kontrol yang tidak menggunakan Model pembelajaran Auditory, Intellectually, Repetition (AIR) di MIN Gebang Udik Kecamatan Gebang Kabupaten Cirebon. Penelitian ini merupakan penelitian Eksperimen yaitu suatu cara untuk mencari hubungan sebab akibat antara dua faktor yang sengaja ditimbulkan oleh peneliti. Analisis data yang digunakan berupa analisis komparatif dengan menggunakan uji " $t$ " dan uji regresi. Hasil penelitian menunjukkan bahwa nilai R Square sebesar 0,604 (kuadrat dari koefisien korelasi 0,777). Dari data tersebut dapat diartikan bahwa 60,4\% pengaruh penerapan Model pembelajaran Auditory, Intellectually, Repetition (AIR) terhadap variable y (hasil belajar), sedangkan sisanya dipengaruhi oleh faktor lain. Pada tabel terlihat bahwa hasil t hitung sebesar 5,919 serta signifikansi 0,000. Untuk t tabel dicari pada taraf signifikansi 5\% dengan derajat kebebasan (df) n-k-1 atau 25-2-1 $=22$. Dengan pengujian 2 sisi (signifikansi $=0,05$ ) maka diperoleh $\mathrm{t}$ tabel sebesar 1,717 . Karena $\mathrm{t}$ hitung $(5,919)$ lebih besar dari t tabel $(1,717)$ maka Ho ditolak, artinya bahwa ada
\end{abstract}


pengaruh penerapan Model pembelajaran Auditory, Intellectually, Repetition (AIR) terhadap Hasil Belajar.

Kata kunci: model pembelajaran auditory, intellectually, repetition (AIR)

\begin{abstract}
This research is based on learning difficulties experienced by students and teachers difficulties in teaching mathematics that impact on student learning outcomes are still very low. The low learning outcomes of students, of course, many factors that cause, such as the classical problem of the application of mathematics learning methods that are still centered on the teacher (teacher center), so that students tend to passively listen to teacher explanations. This study aims to determine whether there is influence of the application of learning Model Auditory, Intellectually, Repetition (AIR) to the Mathematics Learning Outcomes of Materials Division between experimental groups using Auditory, Intellectually, Repetition (AIR) learning Model with a control group that does not use Auditory learning Model, Intellectually, Repetition (AIR) at MIN Gebang Udik Gebang Sub-district, Cirebon District. This study is an experimental research that is a way to find the cause and effect relationship between two factors that deliberately caused by the researcher. Data analysis used in the form of comparative analysis by using test " $t$ ". The results showed that the R Square value of 0.604 (the square of the correlation coefficient 0.777 ). From that data can be interpreted that $60,4 \%$ influence of implementation of learning Model of Auditory, Intellectually, Repetition (AIR) to variable y (learning result), while the rest influenced by other factor. In the table shows that the $t$ count of 5.919 and significant 0.000 . For $t$ table sought at $5 \%$ significant level with degrees of freedom (df) n-k-1 or $25-2-1=22$. With 2-sided test ( significance $=0.05)$ then obtained $t$ table of 1.717 . Because $t$ arithmetic $(5,919)$ is bigger than $\mathrm{t}$ table $(1,717)$ then Ho is rejected, it Means that there is influence of implementation of learning Model of Auditory, Intellectually, Repetition (AIR) to Result Learning
\end{abstract}

Keywords: auditory learning model, intellectually, repetition (AIR)

\title{
PENDAHULUAN
}

"Model pembelajaran adalah suatu perencanaan atau suatu pola yang digunakan sebagai pedoman dalam merencanakan pembelajaran di kelas atau pembelajaran dalam tutorial. Dari pendapat di atas, maka Model pembelajaran digunakan agar kegiatan pembelajaran dapat tersusun secara sistematis", (Trianto, 2014: 51). "Model pembelajaran mempunyai ciri-ciri khusus, diantaranya adalah rasional teoritik logis yang disusun oleh para pencipta atau pengembangnya, landasan pemikiran tentang apa dan bagaimana siswa belajar (tujuan pembelajaran yang akan dicapai), tingkah laku mengajar yang diperlukan agar Model tersebut dapat dilaksanakan dengan berhasil, dan lingkungan belajar yang diperlukan agar tujuan pembelajaran itu dapat tercapai', (Kardi dan Nur dalam Aris Shoimin, 2014: 24).

Dari pendapat pakar di atas, maka dapat disimpulkan bahwa Model pembelajaran mempunyai makna yang lebih luas daripada strategi, metode, atau prosedur karena Model pembelajaran mempunyai ciri khusus yang membedakan dengan strategi, metode, atau prosedur. Model pembelajaran adalah salah satu komponen mutlak dalam menciptakan suasana belajar 
yang aktif, inovatif, kreatif serta menyenangkan (PAIKEM). Model pembelajaran yang hebat serta variatif akan berimplikasi pada ketertarikan maupun motivasi siswa dalam mengikuti proses pembelajaran di kelas. Dengan penerapan kurikulum KTSP maupun kurtilas serta tuntutan untuk mengembangkan Model pembelajaran kreatif maka Guru wajib mengikuti tuntutan perkembangan dunia pendidikan terkini. Guru wajib berani berinovasi serta beradaptasi dengan Model-Model pembelajaran, metode pembelajaran, dan strategi pembelajaran.

Berdasarkan hasil observasi dan wawancara dengan guru kelas di MIN Gebang Udik diperoleh informasi bahwa pembelajaran yang terjadi di MIN Gebang Udik khususnya materi matematika di kelas IV masih menggunakan Model pembelajaran konvensional, sehingga pembelajaran masih terpusat pada guru. Hal ini menyebabkan proses pembelajaran hanya terjadi satu arah, siswa hanya pasif mendengarkan penjelasan guru, sehinga berdampak pada rendahnya hasil belajar siswa, khususnya pada mata pelajaran matematika materi pembagian.

Berdasarkan permasalahan di atas, salah satu Model pembelajaran yang dapat meningkatkan keaktifan siswa di kelas serta berdampak pada meningkatnya hasil belajar siswa adalah Model pembelajaran AIR. Model pembelajaran AIR merupakan singkatan dari Auditory, Intellectually, Repetition. Belajar Model Auditory, yaitu belajar mengutamakan berbicara dan mendengarkan. Sementara menurut Erman Suherman (2008), “auditory bermakna bahwa belajar haruslah melalui mendengarkan, menyimak, berbicara, presentasi, argumentasi, mengemukakan pendapat dan menanggapi".

Sementara itu, Menurut Dave Meier dikutip Aris Shoimin (2014: 29),'intellectually menunjukkan apa yang dilakukan pembelajaran dalam pemikiran suatu pengalaman dan menciptakan hubungan makna, rencana dan nilai dari pengalaman tersebut' Intellectually juga bermakna belajar haruslah menggunakan kemampuan berpikir (mind-on), haruslah dengan konsentrasi pikiran dan berlatih menggunakannya melalui bernalar, menyelidiki, mengidentifikasi, menemukan, mencipta, mengonstruksi, memecahkan masalah, dan menerapkan.

Sedangkan repetition Menurut Erman Suherman (2008) "merupakan pengulangan, dengan tujuan memperdalam dan memperluas pemahaman siswa yang perlu dilatih melalui pengerjaan soal, pemberian tugas, dan kuis". Pengulangan dalam kegiatan pembelajaran dimaksudkan agar pemahaman siswa lebih mendalam, disertai pemberian soal dalam bentuk tugas latihan atau kuis. Dengan pemberian tugas, diharapkan siswa lebih berlatih dalam menggunakan pengetahuan yang didapat dalam menyelesaikan soal dan mengingat apa yang telah diterima. Sementara pemberian kuis dimaksudkan agar siswa siap menghadapi ujian atau tes yang dilaksanakan sewaktu-waktu serta melatih daya ingat. Dengan demikian penulis dapat menyimpulkan bahwa Pada pembelajaran AIR, pembelajaran difokuskan pada pemberian 
pengalaman belajar secara langsung dan menyenangkan. Pengalaman belajar secara langsung dengan cara belajar mendengarkan atau menyimak (auditory), belajar dengan berpikir (intellectually) dan belajar dengan pengulangan (repetition).

Matematika sebagai salah satu mata pelajaran yang dalam KTSP (2006) yang disempurnakan pada kurikulum 2013, mencantumkan tujuan pembelajaran matematika sebagai berikut: 1) memahami konsep matematika, menjelaskan keterkaitan antarkonsep dan mengaplikasikan konsep atau algoritma secara luwes, akurat, efisien, dan tepat dalam pemecahan masalah, 2) menggunakan penalaran pada pola dan sifat, melakukan manipulasi matematika dalam membuat generalisasi, menyusun bukti atau menjelaskan gagasan dan pernyataan matematika, 3) memecahkan masalah, 4) mengomunikasikan gagasan dengan simbol, tabel, diagram, atau media lain untuk memperjelas keadaan atau masalah, 5) memiliki sikap menghargai kegunaan matematika dalam kehidupan dan sikap rasa ingin tahu.

Melihat tujuan di atas, maka guru matematika harus selalu berusaha untuk meningkatkan motivasi dan hasil belajar siswa pada saat pembelajaran, khususnya pada mata pelajaran Matematika, salah satunya dengan menggunakan strategi, Model pembelajaran dan metode yang aktif dan menyenangkan. Pembelajaran Matematika di sekolah yang diteliti sangat jauh dari pembelajaran yang ada pada saat ini, yakni guru pengampu mata pelajaran Matematika dalam mengajar masih menggunakan metode konvensional (ceramah). Sehingga semua itu membuat hasil belajar siswa tidak memuaskan. Oleh karena itu, peneliti akan mencba menerapkan Model pembelajaran Auditory, Intellectually, Repetition (AIR) untuk mengetahui apakah Model pembelajaran tersebut berpengaruh terhadap hasil belajar siswa pada mata pelajaran matematika materi pembagian. Diharapkan dengan penerapan Model pembelajaran Auditory, Intellectually, Repetition (AIR) tersebut dapat meningkatkan hasil belajar siswa kelas IV MIN Gebang Udik Kecamatan Gebang Kabupaten Cirebon.

\section{METODE PENELITIAN}

Dalam penelitian ini peneliti menggunakan desain penelitian Nonequivalent Control Group Desain.

$\begin{array}{lll}\mathrm{Q}_{1} & \mathrm{X} & \mathrm{Q}_{2} \\ \mathrm{O}_{3} & & \mathrm{O}_{4}\end{array}$

Keterangan :

$\mathrm{Q}_{1} \quad=$ Pre-test kelas eksperimen

$\mathrm{Q}_{2} \quad=$ Post-test kelas eksperimen

$\mathrm{O}_{3} \quad=$ Pre-test kelas kontrol

$\mathrm{O}_{4} \quad=$ Post-test kelas kontrol

$\mathrm{X}=$ diberi perlakuan dengan Model pembelajaran Auditory, Intellectually, Repetition (AIR) 
Sugiyono (2014: 79) mengemukakan bahwa dalam desain ini terdapat dua kelompok yang dipilih secara random kemudian diberi Pre-test untuk mengetahui keadaan awal adakah perbedaan antara kelompok eksperimen dan kelompok Kontrol. Hasil Pre-test yang baik apabila nilai kelompok eksperimen tidak berbeda secara signifikan. Pengaruh perlakuan adalah $\left(\mathrm{O}_{2}-\mathrm{O}_{1}\right)$ $-\left(\mathrm{O}_{4}-\mathrm{O}_{3}\right)$.

Sementara itu, variabel dalam penelitian ada dua, yakni variabel bebas (Independent Variable) dan variabel terikat (Dependent Variable). "Variabel adalah objek penelitian, atau apa yang menjadi titik perhatian suatu penelitian" (Arikunto, 2013: 169). Variabel bebas (Independent Variable) dalam penelitian ini adalah Model pembelajaran Auditory, Intellectually, Repetition (AIR). Sedangkan Variabel Terikatnya (Dependent Variable) adalah hasil belajar siswa pada mata pelajaran matematika materi pembagian.

Populasi dalam penelitian ini adalah seluruh siswa MIN Gebang Udik yang berjumlah 311 siswa. Sedangkan yang menjadi sampel adalah kelas IV. Kelas IVA yang akan mendapat treatment berupa Model pembelajaran Auditory, Intellectually, Repetition (AIR) atau kelas eksperimen. Sedangkan kelas IV B menjadi kelas kontrol yang tidak mendapatkan treatment. Penentuan sampel ini menggunakan teknik purposive sampling. Purposive sampling adalah teknik penentuan sampel dengan pertimbangan tertentu. Alasan peneliti mengambil kelas IV dengan jumlah 47 siswa karena kelas IV termasuk kelas tinggi, karakter siswa sudah mulai mandiri, sudah ada rasa tanggung jawab pribadi, sudah menunjukkan sikap yang kritis dan rasional, dan suka membentuk kelompok sebaya sehingga dapat diajak untuk belajar berkelompok dengan menerapkan Model pembelajaran Auditory, Intellectually, Repetition (AIR).

Dalam penelitian ini, teknik pengumpulan data yang digunakan adalah lembar angket, lembar tes, dan dokumentasi. “Angket (Kuisioner) merupakan teknik pengumpulan data yang dilakukan dengan cara memberi seperangkat pertanyaan atau pernyataan tertulis kepada responden untuk dijawabnya" (Sugiyono :2014). Angket ini berisikan pernyataan yang berkaitan dengan mata pelajaran matematika materi pembagian dengan menggunakkan penerapan Model pembelajaran Auditory, Intellectually, Repetition (AIR). Soal tes yang digunakan dalam penelitian ini adalah soal tes berbentuk pilihan ganda yang dibuat sendiri oleh peneliti yang digunakan untuk memperoleh data mengenai hasil belajar matematika dengan menggunakan Model pembelajaran Auditory, Intellectually, Repetition (AIR) pada materi pembagian. Soal tes ini dibuat sesuai dengan materi pada saat dilakukan penelitian. Soal tes dalam bentuk pilihan ganda disusun sebanyak 30 pertanyaan berdasarkan tiga pilihan ganda, dimana pilihan jawaban yang benar bernilai 1 dan jawaban yang salah bernilai 0. Dokumentasi dalam penelitian ini berupa pengambilan dan pengumpulan data gambar berupa foto sebagai media pendukung 
kegiatan penelitian ini sekaligus bukti penguat akan adanya proses penelitian ini. Sementara itu teknik analisis data dalam penelitian ini menggunakan uji regeresi sederhana.

\section{HASIL PENELITIAN DAN PEMBAHASAN}

\section{A. Hasil Penelitian}

Untuk memperoleh data tentang penerapan Model Auditory, Intellectually, Repetition (AIR), peneliti menggunakan angket yang terdiri dari 20 item pernyataan. Adapun gambaran data yang diperoleh dari hasil angket siswa tentang penerapan Model Auditory, Intellectually, Repetition (AIR) dapat dilihat pada tabel 1 berikut :

Tabel 1. Skor Angket

\begin{tabular}{ccccccccccc}
\hline \multirow{2}{*}{ NO } & \multicolumn{1}{c}{$\mathbf{1}$} & \multicolumn{2}{c}{$\mathbf{2}$} & \multicolumn{3}{c}{$\mathbf{3}$} & \multicolumn{3}{c}{ JUMLAH } \\
\cline { 2 - 10 } & $\mathbf{F}$ & $\mathbf{S}$ & $\mathbf{F}$ & $\mathbf{S}$ & $\mathbf{F}$ & $\mathbf{S}$ & $\mathbf{F}$ & $\mathbf{S}$ & $\mathbf{F}$ & $\mathbf{S}$ \\
\hline 1 & 0 & 0 & 3 & 6 & 7 & 21 & 15 & 60 & 25 & 87 \\
\hline 2 & 0 & 0 & 3 & 6 & 9 & 27 & 13 & 52 & 25 & 85 \\
\hline 3 & 0 & 0 & 2 & 4 & 8 & 24 & 15 & 60 & 25 & 88 \\
\hline 4 & 1 & 1 & 2 & 4 & 11 & 33 & 11 & 44 & 25 & 82 \\
\hline 5 & 0 & 0 & 1 & 2 & 11 & 33 & 13 & 52 & 25 & 87 \\
\hline 6 & 2 & 2 & 2 & 4 & 10 & 30 & 11 & 44 & 25 & 80 \\
\hline 7 & 2 & 2 & 1 & 2 & 12 & 36 & 10 & 40 & 25 & 80 \\
\hline 8 & 1 & 1 & 2 & 4 & 10 & 30 & 12 & 48 & 25 & 83 \\
\hline 9 & 1 & 1 & 2 & 4 & 12 & 36 & 10 & 40 & 25 & 81 \\
\hline 10 & 2 & 2 & 3 & 6 & 9 & 27 & 11 & 44 & 25 & 79 \\
\hline 11 & 1 & 1 & 5 & 10 & 7 & 21 & 12 & 48 & 25 & 80 \\
\hline 12 & 0 & 0 & 3 & 6 & 6 & 18 & 16 & 64 & 25 & 88 \\
\hline 13 & 2 & 2 & 1 & 2 & 7 & 21 & 15 & 60 & 25 & 85 \\
\hline 14 & 1 & 1 & 2 & 4 & 9 & 27 & 13 & 52 & 25 & 84 \\
\hline 15 & 0 & 0 & 4 & 8 & 6 & 18 & 15 & 60 & 25 & 86 \\
\hline 16 & 0 & 0 & 3 & 6 & 7 & 21 & 15 & 60 & 25 & 87 \\
\hline 17 & 1 & 1 & 1 & 2 & 9 & 27 & 14 & 56 & 25 & 86 \\
\hline 18 & 0 & 0 & 2 & 4 & 10 & 30 & 12 & 48 & 24 & 82 \\
\hline 19 & 1 & 1 & 6 & 12 & 6 & 18 & 12 & 48 & 25 & 79 \\
\hline 20 & 0 & 0 & 5 & 10 & 10 & 30 & 10 & 40 & 25 & 80 \\
\hline JUMLAH & 15 & 15 & 53 & 106 & 176 & 528 & 255 & 1020 & 499 & 1669 \\
\hline
\end{tabular}

Berdasarkan uraian prosentase angket pada tabel 1 di atas, terlihat bahwa jumlah skor total hasil angket sebesar 1669. Dengan demikian respon angket variabel penerapan Model pembelajaran Auditory, Intellectually, Repetition (AIR) terhadap hasil belajar siswa pada mata pelajaran matematika materi pembagian di kelas IV MIN GebangUdik, menurut 25 responden, yaitu 1669 : 2000 × 100\% = 83,45\% dari kriteria yang ditetapkan. Apabila diinterpretasi, nilai $83,45 \%$ terletak pada daerah Sangat Kuat. 
Tingkatan Kontinum angket

Penggunaan Model pembelajaran Auditory, Intellectually, Repetition (AIR)

$$
83,45
$$

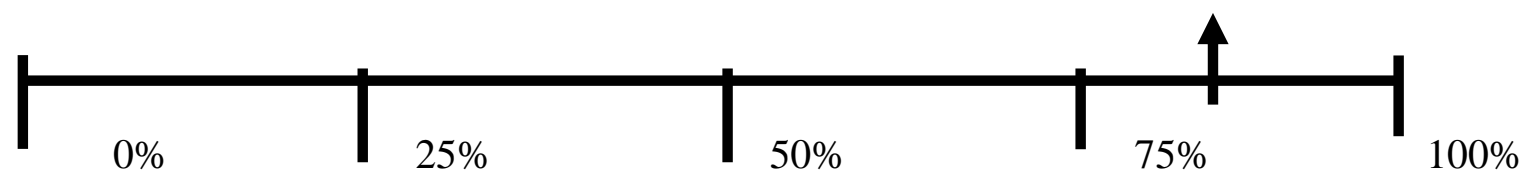

Sementara itu, hasil belajar pre-test dan post-test kelas eksperimen sebagaimana tabel 2 berikut:

Tabel 2. Hasil Belajar Kelas Eksperimen

\begin{tabular}{lrrr}
\hline \multicolumn{3}{c}{ Statistics } \\
\hline & $\begin{array}{c}\text { Pre-test } \\
\text { Eksperimen }\end{array}$ & $\begin{array}{c}\text { Post-test } \\
\text { Eksperimen }\end{array}$ \\
\hline \multirow{2}{*}{$\mathrm{N}$} & Valid & 25 & 25 \\
\cline { 2 - 4 } & Missing & 0 & 0 \\
\hline Mean & 53,4000 & 83,0000 \\
\hline Median & 55,0000 & 85,0000 \\
\hline Mode & $45,00^{\mathrm{a}}$ & 85,00 \\
\hline Minimum & 35,00 & 70,00 \\
\hline Maximum & 65,00 & 95,00 \\
\hline
\end{tabular}

A. Multiple Modes exist. The smallest value is shown

Berdasakan tabel 2 di atas terlihat bahwa jumlah responden sebanyak 25 siswa. Missing 0 menunjukkan bahwa data yang hilang adalah nol, dengan demikian tidak ada data yang belum diproses. Mean atau rata-rata Pre-test sebesar 53,4. Median diperoleh 55, Mode didapat 45 sementara nilai minimal dan maksimal masing-masing sebesar 35 dan 65 . Sedangkan Mean atau rata-rata Post-testt sebesar 83,00. Median diperoleh 85, Mode didapat 85 sementara nilai minimal dan maksimal masing-masing sebesar 70 dan 95 . Hal ini menunjukkan bahwa rata-rata hasil belajar antara Pre-test dengan Post-test pada kelas eksperimen terdapat perbedaan.

Tabel 3. Hasil Belajar Kelas Kontrol

\begin{tabular}{lrrr}
\hline \multicolumn{3}{c}{ Statistics } \\
\hline \multirow{2}{*}{$\mathrm{N}$} & Pre-test Kontrol & Post-test Kontrol \\
\cline { 2 - 4 } & Valid & 22 & 22 \\
\cline { 2 - 4 } Missing & 0 & 0 \\
\hline Mean & 51,8182 & 70,0000 \\
\hline Median & 52,5000 & 70,0000 \\
\hline Mode & 55,00 & 70,00 \\
\hline Minimum & 35,00 & 55,00 \\
\hline Maximum & 70,00 & 80,00 \\
\hline
\end{tabular}


Berdasakan tabel 3 terlihat bahwa jumlah responden sebanyak 22 siswa. Missing 0 menunjukkan bahwa data yang hilang adalah nol, dengan demikian tidak ada data yang belum diproses. Mean atau rata-rata Pre-test sebesar 51,82. Median diperoleh 52,5, Mode didapat 55 sementara nilai minimal dan maksimal masing-masing sebesar 35 dan 70. Sedangkan Mean atau rata-rata Post-test sebesar 70. Median diperoleh 70, Mode didapat 70 sementara nilai minimal dan maksimal masing-masing sebesar 55 dan 80.

Tabel 4. N-Gain Hasil Belajar

\begin{tabular}{|c|c|c|c|c|c|c|c|c|}
\hline \multirow[b]{3}{*}{ Kelas } & \multicolumn{6}{|c|}{ Kriteria Indeks Gain Tiap Siswa } & \multirow{3}{*}{$\begin{array}{c}\text { Hasil } \\
\text { Rataan } \\
\text { Indeks } \\
\text { Gain }\end{array}$} & \multirow{3}{*}{$\begin{array}{c}\text { Kriteria } \\
\text { Indeks } \\
\text { Gain }\end{array}$} \\
\hline & \multicolumn{2}{|c|}{ Rendah } & \multicolumn{2}{|c|}{ Sedang } & \multicolumn{2}{|c|}{ Tinggi } & & \\
\hline & $\mathbf{F}$ & Persen & $\mathbf{F}$ & Persen & $\mathbf{F}$ & Persen & & \\
\hline EKSPERIMEN & 1 & $4,00 \%$ & 17 & $68,00 \%$ & 7 & $28,00 \%$ & 0,6304 & Tinggi \\
\hline KONTROL & 4 & $18,18 \%$ & 18 & $81,82 \%$ & 0 & $0,00 \%$ & 0,3684 & Sedang \\
\hline
\end{tabular}

Berdasarkan tabel 4 di atas, hasil analisis indeks gain ternormalisasi pada kelas eksperimen menunjukkan kategori rendah 1 siswa (4\%), jumlah siswa yang termasuk ke dalam kategori sedang yaitu sebanyak 17 siswa (68\%) dan yang termasuk dalam kategori tinggi sebanyak 7 siswa (28\%). Peningkatan rata-rata indek gain ternormalisasi dari Pre-test ke Post-test adalah sebesar 0,6304 dengan kategori tinggi. Sementara gain pada kelas kontrol menunjukkan kategori rendah 4 siswa $(18,82 \%)$, tidak ada siswa yang mendapatkan kategori sedang dan tinggi. Peningkatan rata-rata indek gain ternormalisasi dari Pre-test ke Post-test adalah sebesar 0,3684 dengan kategori sedang

Tabel 5. Determinasi R Square

\begin{tabular}{llccc}
\hline \multicolumn{4}{c}{ Model Summary } \\
\hline Model & $\mathrm{R}$ & $\mathrm{R}$ & Adjusted R & Std. Error of the \\
& & Square & Square & Estimate \\
\hline 1 &, $777^{\mathrm{a}}$ &, 604 &, 586 & 404,600 \\
\hline $\begin{array}{l}\text { a. Predictors: (Constant), penggunaan Model pembelajaran Auditory, } \\
\text { Intellectually, Repetition (AIR) }\end{array}$ & \\
\hline
\end{tabular}

Pada tabel 5 di atas terdapat R Square sebesar 0,604 (kuadrat dari koefisien korelasi 0,777). R Square disebut koefisien determinan yang dalam hal ini 60,4\%. Dari harga tersebut dapat diartikan bahwa 60,4\% pengaruh penggunaan penggunaan Model pembelajaran Auditory, Intellectually, Repetition (AIR) terhadap hasil belajar matematika materi pembagian kelas IV MIN Gebang Udik, sedangkan sisanya dipengaruhi oleh faktor lain. 
Tabel 6. Anova

\begin{tabular}{|c|c|c|c|c|c|c|}
\hline \multicolumn{7}{|c|}{ ANOVA $^{\text {a }}$} \\
\hline \multicolumn{2}{|c|}{ Model } & $\begin{array}{l}\text { Sum of } \\
\text { Squares }\end{array}$ & Df & Mean Square & $\mathrm{F}$ & Sig. \\
\hline & Regression & 573,487 & 1 & 573,487 & 35,033 &, $000^{\mathrm{b}}$ \\
\hline & Residual & 376,513 & 23 & 16,370 & & \\
\hline 1 & Total & 950,000 & 24 & & & \\
\hline \multicolumn{7}{|c|}{ a. Dependent Variable: hasil belajar Matematika } \\
\hline $\begin{array}{l}\text { b. Pre } \\
\text { Intelle }\end{array}$ & $\begin{array}{l}\text { dictors: (Con } \\
\text { ctually, Rep }\end{array}$ & $\begin{array}{l}\text { ), penggunaa } \\
\text { n (AIR) }\end{array}$ & $\mathrm{Mo}$ & 1 pembelajara & Audito & \\
\hline
\end{tabular}

Hasil uji anova pada tabel 6 di atas menunjukkan bahwa nilai $\mathrm{F}$ hitung sebesar 35,033 dengan taraf signifikansi sebesar 0,000. Nilai ini kemudian dibandingkan dengan F tabel yang dihitung pada derajat bebas pembilang (df pembilang) sebesar 1 dan derajat bebas penyebut (df penyebut) sebesar 23 pada taraf 0,05 yang nilainya adalah 4.28. Tampak sangat jelas bahwa nilai $\mathrm{F}$ hitung $(35,033)$ lebih besar dari Ftabel (4.28). Sehingga dapat disimpulkan bahwa Model yang dihasilkan adalah baik. Hal ini menunjukkan Model regresi linear dapat digunakan.

Tabel 7. Uji Regresi

\begin{tabular}{|c|c|c|c|c|c|c|}
\hline \multicolumn{7}{|c|}{ Coefficients $^{a}$} \\
\hline \multirow{2}{*}{\multicolumn{2}{|c|}{ Model }} & \multicolumn{2}{|c|}{$\begin{array}{l}\text { Unstandardized } \\
\text { Coefficients }\end{array}$} & $\begin{array}{l}\text { Standardized } \\
\text { Coefficients }\end{array}$ & $\mathrm{T}$ & Sig. \\
\hline & & $\mathrm{B}$ & Std. Error & Beta & & \\
\hline & (Constant) & 31,035 & 8,817 & & 3,520 &, 002 \\
\hline 1 & $\begin{array}{c}\text { penggunaan Model pembelajaran } \\
\text { Auditory, Intellectually, Repetition (AIR) }\end{array}$ & ,780 & ,132 & ,777 & 5,919 & 000 \\
\hline
\end{tabular}

a. Dependent Variable: hasil belajar Matematika

$\mathbf{Y}=\mathbf{a}+\mathbf{b X}$

$\mathrm{Y}$ adalah variabel dependent, dalam hal ini adalah Hasil Belajar, dan X adalah variabel independent, dalam hal ini adalah penggunaan Model pembelajaran Auditory, Intellectually, Repetition (AIR). Sedangkan a dan b adalah nilai konstanta yang dicari.

Berdasarkan hasil regresi diketahui nilai constant-nya adalah 31,035 dan nilai Hasil Belajar adalah 0,780. Dari keterangan tersebut kita dapat memperoleh persamaan regresi sebagai berikut:

$\mathbf{Y}=31,035+0,780 \mathbf{X}$

Nilai konstanta dari koefficien regresi sebesar 31,035, hal ini menyatakan bahwa jika tidak ada kenaikan nilai atau skor dari variabel Penggunaan Model pembelajaran Auditory, Intellectually, Repetition (AIR), maka variabel Penggunaan Model pembelajaran Auditory, Intellectually, Repetition (AIR) adalah 31,035. Koefficien regresi sebesar 0,780 menyataakan 
bahwa setiap terjadi penambahan skor variabel Penggunaan Model pembelajaran Auditory, Intellectually, Repetition (AIR) akan dapat menambah kenaikan variabel Hasil Belajar.

Setelah megetahui besarnya koefisien regresi, maka perlu dilakukan pengujian hipotesis untuk megetahui apakah terdapat pengaruh atau tidak. Uji hipotesis dapat dinyatakan dengan membandingkan nilai signifikan yaitu

Jika nilai signifikansi $>0,05$ dan $t_{\text {hitung }}<\mathrm{t}_{\text {tabel }}$, maka $\mathrm{H}_{0}$ diterima

Jika nilai signifikansi $<0,05$ dan $\mathrm{t}_{\text {hitung }}<\mathrm{t}_{\text {tabel }}$, maka $\mathrm{H}_{0}$ ditolak

Jika $t_{\text {tabel }}$ dicari dengan $\alpha=0,05$ dan (df) $n-k-1$ atau 25-2-1 $=22$, jadi $t_{\text {tabel }}=1,717$

Berdasarkan hasil uji regresi di atas nilai signifikansi sebesar 0,000. Karena nilai signifikansi lebih kecil dari 0,05 dan t hitung $(5,919)$ lebih besar dari t tabel $(1,717)$ maka Ho ditolak, artinya bahwa ada pengaruh Penggunaan Model pembelajaran Auditory, Intellectually, Repetition (AIR) terhadap Hasil Belajar.

\section{B. Pembahasan}

Dari uraian hasil penelitian di atas terlihat bahwa rata-rata nilai Pre-test yang diperoleh di kelas eksperimen sebesar 53,4. Sedangkan rata-rata nilai Post-test yang diperoleh di kelas eksperimen yang diberi perlakuan dengan menerapkan Model pembelajaran Auditory, Intellectually, Repetition (AIR) sebesar 83,00. Dengan demikian terbukti bahwa pembelajaran yang menggunakan Model pembelajaran Auditory, Intellectually, Repetition (AIR) mengalami perubahan yang baik terhadap hasil pembelajaran.

Berdasarkan hasil analisis uji t diperoleh t hitung sebesar 5,919 serta signifikan 0,000. Untuk t tabel dicari pada taraf signifikan 5\% dengan derajat kebebasan (df) n-k-1 atau 25-2-1 $=22$. Dengan pengujian 2 sisi (signifikansi $=0,05$ ) hasil diperoleh untuk t tabel sebesar 1,717. Karena t hitung $(5,919)$ lebih besar dari t tabel $(1,717)$ maka Ho ditolak, artinya bahwa ada pengaruh penggunaan Model pembelajaran Auditory, Intellectually, Repetition (AIR) terhadap hasil belajar matematika materi pembagian di kelas IV. Sehingga dapat disimpulkan bahwa pembelajaran yang menggunakan Model pembelajaran Auditory, Intellectually, Repetition (AIR) dapat diterima, artinya hasil belajar matematika siswa kelas IV MIN Gebang Udik Kecamatan Gebang Kabupaten Cirebon siswa kelas eksperimen ada perubahan yang baik. Hal ini dikarenakan Model pembelajaran Auditory, Intellectually, Repetition (AIR) lebih menantang, menarik dan menyenangkan bagi siswa. Penggunaan Model pembelajaraan AIR sangat berpengaruh pada hasil belajar siswa sehingga hasil belajar siswa tercapai dengan optimal. Melalui Model pembelajaran Auditory, Intellectually, Repetition (AIR) siswa dapat ikut serta dalam kegiatan pembelajaran sehingga mempunyai pengalaman 
langsung dan siswa lebih mudah mengingat materi yang sudah diberikan. Dalam kegiatan pembelajaran, respon siswa terhadap Model pembelajaran yang diterapkan mempunyai arti yang sangat penting dan perlu diperhatikan karena dapat menunjang proses belajar siswa.

Berdasarkan hasil angket yang telah disebarkan pada kelas eksperimen, rata-rata respon siswa terhadap Model pembelajaran Auditory, Intellectually, Repetition (AIR)sebesar 83,45 yang tergolong sangat kuat. Hal ini menunjukkan bahwa rata-rata siswa merespon dengan baik pembelajaran dengan menggunakan Model pembelajaran Auditory, Intellectually, Repetition (AIR).

\section{SIMPULAN}

Berdasarkan hasil penelitian yang dilaksanakan di kelas IV MIN Gebang Udik, penulis dapat mengambil kesimpulan bahwa penerapan model pembelajaran Auditory, Intellectually, Repetition (AIR) menurut 25 responden pada skor angket yaitu mencapai 83,45\% dari kriterium yang ditetapkan. Apabila diinterpretasikan nilai $84,1 \%$ terletak pada daerah sangat kuat artinya sebagian besar responden menerima dan senang dengan penerapan model pembelajaran Auditory, Intellectually, Repetition (AIR)) dalam mata pelajaran matematika di kelas IV ini. Oleh karena itu terdapat perbedaan hasil belajar antara siswa yang mendapat perlakuan belajar dengan menggunakan Model pembelajaran Auditory, Intellectually, Repetition (AIR) dengan siswa yang tidak diberi perlakuan atau hanya menggunakan pembelajaran konvensional saja. Mean atau ratarata Pre-test pada kelas eksperimen sebesar 53,4 dan Mean atau rata-rata Post-test sebesar 83,00. Sedangkan Mean atau rata-rata Pre-test pada kelas kontrol sebesar 51,82 dan Mean atau rata-rata Post-testnya sebesar 70. Jadi terdapat perbedaan hasil pada kedua kelas tersebut dilihat dari Pre-test dan Post-testnya. Tetapi hasil Pre-test dan Post-test kelas ekperimen jauh lebih besar dibandingkan hasil Pre-test dan Post-test pada kelas kontrol.

Berdasarkan dari nilai R Square sebesar 0,604 (kuadrat dari koefisien korelasi 0,777).R Square disebut koefisien determinan yang dalam hal ini 60,4\%. Dari harga tersebut dapat diartikan bahwa 60,4\% pengaruh penggunaan penggunaan Model pembelajaran Auditory, Intellectually, Repetition (AIR) terhadap hasil belajar matematika materi pembagian kelas IV MIN GebangUdiksedangkan sisanya dipengaruhi oleh faktor lain. 


\section{DAFTAR PUSTAKA}

Arikunto, Suharsimi. 2013. Prosedur Penelitian: Suatu Pendekatan Praktek. Jakarta: Rineka Cipta.

Shoimin, Aris. 2014. Model Pembelajaran Inovatif dalam Kurikulum 2013. Yogyakarta : ArRuzz Media.

Sugiyono. 2014. Metode Penelitian Pendidikan Pendekatan Kuantitatif, Kualitatif, dan R\&D. Bandung: Alfabeta.

Suherman, Erman, dkk., 2003. Strategi Pembelajaran Matematika Kontemporer. Bandung: Jurusan Pendidikan Matematika Fakultas Pendidikan Matematika Universitas Pendidikan Indonesia.

Trianto. 2014. Model Pembelajaran Terpadu . Jakarta : Bumi Aksara. 